\title{
Shaq is Not Alone: \\ Free-Throws in the Final Moments of a Basketball Game
}

\author{
by \\ Miguel-Ángel Gómez¹, Simcha Avugos ${ }^{2}$, Miguel-Ángel Oñoro ${ }^{1}$, Alberto Lorenzo', \\ Michael Bar-Eli2,3
}

\begin{abstract}
It has been previously observed that basketball free-throw (FT) shooting efficiency decreases towards the end of the game. The aim of the current study was to explore possible determinants for this distinctive pattern during close games (point differential of equal or under 2 points during the final minute of the game). A sample of shots attempted by 92 players in the Spanish professional basketball league (ACB) was collected. Several personal (age, experience, playing position and career FT percentage) and contextual (team ability, competition stage, game location, seconds remaining and score differential) variables were considered for the analysis of the data. The effects of the predictor variables on the players' performance were analyzed according to two game contexts (FT attempted during the final minute or the last pair of FTs) using binomial logistic regression analysis. The results showed that during the final minute the only statistically significant variable was being in the center playing position $(O R=1.58)$, which decreased the FT shooting percentage compared to forwards and guards. In addition, the results during the last pair of FTs showed that the playing position of guards $(O R=1.70)$ and centers $(O R=2.22)$ was significant (a decrease in their FT percentage). Conversely, the score differential when tied $(O R=-1.17)$ or losing $(O R=-2.43)$ was significant, reflecting a lower probability of missing the shot. The results were interpreted and discussed from the viewpoints of crisis theory and the literature on choking in athletic performance.
\end{abstract}

Key words: performance analysis, choking, pressure conditions.

\section{Introduction}

Free-throws (FTs), or foul shots, are commonly shot in pairs, and they are always shot from the same location (the foul line), without defensive pressure. Hence, they are relatively "easy" points to earn, and thus we would expect the average FT shooting percentage in professional basketball to be much higher from the line than while shooting from the field. However, FTs are too often not successfully made, even by highly trained athletes. A notorious example would be Shaquille O'Neal, who had a 1,207-game career in the NBA, with 11,225 FTs attempted and an average efficiency of just $52.7 \%$ (retrieved from www.basketball-reference.com). His relatively low success rate in FT shooting is especially surprising if one considers his career field goal percentage $(\mathrm{FG} \%=58.2 \%$ ), which is not much different from his efficiency from the line.

FTs account for a large share of all scoring per game: between 20-30\% (Kozar et al., 1994). This value of FTs is even more significant during the final few minutes of games with close margins of victory (Ferreira et al., 2014; Kozar et al., 1994; Malarranha et al., 2013). Goldman and Rao (2012) established a plausible proxy of pressure that was directly related to the expected effect on the

1 - Faculty of Physical Activity and Sport Sciences, Polytechnic University of Madrid, Spain.

2 - The Zinman College of Physical Education and Sport Sciences, Wingate Institute, Netanya, Israel.

3 - Department of Business Administration, Faculty of Management, Ben-Gurion University of the Negev, Beer-Sheva, Israel. 
outcome of the game of each and every FT shot attempted, however, with no particular attention paid to FTs attempted towards the end of close games. Based on this rationale, the present study aimed to explore possible determinants for the decrease of basketball FT shooting success rate towards the end of the game.

According to the game regulations (FIBA, 2014), FTs should be executed within no more than $5 \mathrm{~s}$ before the game can be continued. It has been previously observed that the FT shooting success rate decreases towards the end of a game, most likely due to the stressful conditions under which these shots are attempted (Worthy et al., 2009). In particular, sport psychologists have argued that performance of basketball players is highly vulnerable to psychological crisis during the last $5 \mathrm{~min}$ of the game (see for a review BarEli, 1997). Within this final phase, the likelihood of such a decline in performance is even greater during the very last minute of the game (Bar-Eli and Tractinsky, 2000). These pressure-associated performance declines are particularly evident in close or tied games, when the pressure is extremely high on the players (Bar-Eli et al., 1991; Solomonov et al., 2015).

The literature on choking attempts to explain how and why such changes in performance occur under pressure (Baumeister, 1984; see for a review Beilock and Gray, 2007). Two distinct processes are suggested: either the experience of high levels of anxiety and self-doubt under stressful conditions, which might reduce the performer's attentional capacity (Distraction Theory - Beilock et al., 2004; Oudejans et al., 2011), or alternatively the increase of selfconsciousness about how to perform the task adequately, which results in over-attention to the execution process itself, instead of "just doing it" (Self-focus Theory - Beilock and Gray, 2012; Castaneda and Gray, 2007; DeCaro et al., 2011). Furthermore, the literature on motor learning and performance (e.g., Schmidt and Wrisberg, 2004; Mikołajec, et al. 2012) describes FT shooting as being a closed motor skills task (i.e., having limited degrees of freedom in executing the task), which requires quiet concentration in order to succeed. Bringing together these two sources of literature, we realize that the experience of choking is primarily attributed to an increase in the performer's level of anxiety, which in the case of FTs is assumed to produce attentional disturbance when shooting. Therefore, players will perform a task with poorer ability relative to their normal performance (i.e., their regular season FT shooting percentage), due to a stressful situation, for example throwing to win with no time left (Beilock and Carr, 2005).

More recent research has given its attention to the value of FTs towards the end of games (Goldman and Rao, 2012; Gomez et al., 2015; Worthy et al., 2009). Looking at the contexts of the last $5 \mathrm{~min}$ and overtime in close games (i.e., less than or equal to 3 points in the score difference), Gómez and colleagues (2015) found that the outcome of FTs attempted in both of these contexts played an important role in determining whether a team won or lost the game. Furthermore, when facing a stressful situation, players demonstrated a faster execution and shorter response as compared with behaviors displayed during training sessions, which reduced their chances of successfully making the shots. Similarly, it has been observed that NBA players miss more of their shots when their team is winning or losing the game by only one point (Worthy et al., 2009). It was therefore concluded that pressure might produce a contextual prevention focus, which interacted with the general focus of avoiding losing and favoring winning, as suggested by the Prospect Theory (Kahneman and Tversky, 1979). Even when the so-called "clutch reputation" was tested, shooting was not found to improve in FTs attempted by the best NBA clutch players during the last $5 \mathrm{~min}$ of the games (Solomonov et al., 2015).

In line with these results, Cao and colleagues (2011) found that FT shooting success in the NBA league decreased by 5 to $10 \%$ during the last $15 \mathrm{~s}$ of the games, mostly as the score differential and time left until the end of the game decreased. However, the competition stage (regular season vs. playoff) and game location (home vs. away) had no significant effect on the outcomes. In stark contrast, a supportive audience was found to have a detrimental effect even for experienced athletes in a Goldman and Rao's (2012) study, as home FT shooters were significantly less successful in clutch situations than the road players ("home choke"), with the effect being larger for poor shooters.

Previous studies have pointed to several 
possible "subjective" (e.g., motivation, mental stability, physical fatigue) as well as "objective" (e.g., training tasks, intensity, training loads) determinants of shooting performance in pressure situations (Zuzik, 2011), as suggested by the canonical literature on human functioning (e.g., Bandura, 1986; Lewin, 1951). In particular, the amount of experience players acquired in the field was found to greatly affect their shooting at the FTs line (Liao and Masters, 2002; Sindik, 2015). Furthermore, the playing position and physiological attributes of players in the various positions (e.g., height) were also found to influence FT shooting efficiency: shorter players (i.e., guards and forwards) were more successful than taller players (i.e., centers; Sindik, 2015), and guards were more successful than forwards and centers (Sampaio et al., 2006).

To summarize, the previous studies on FTs have collectively considered a number of different possible determinants of shooting performance in pressured situations. We propose here an integrative approach for the study of the formerly observed decrease in FT shooting efficiency towards the end of basketball games, taking into account both personal and contextual factors (Beilock et al., 2004; Hill et al., 2009). At the end of games, a larger number of FTs are usually attempted due to the increased effort of both teams to reduce the game pace, as well as the score differential, via committed fouls (Gabel and Redner, 2012). In fact, close games are often decided by FTs made under these pressured conditions (Worthy et al., 2009). Therefore, based on previous studies (e.g., Liao and Masters, 2002; Sampaio et al., 2006; Sindik, 2015), we expected that the players' age, amount of experience and playing position would influence their shooting percentage at the FTs line, while considering the final minute and last pair of FTs attempted in close games. We also expected that FT shooting efficiency would highly depend on the score differential and the time left for the game to be ended (Cao et al., 2011).

\section{Methods}

\section{Participants}

Data on 104 close games from the 1st men's Spanish professional basketball league (ACB) was collected. Statistics were obtained from play-by-play box scores from the ACB league official open access web domain (www.acb.com). The sample included 92 games from the regular season and 12 games from the knockout stage of four seasons (2011-2012 to 2014-2015). The score differential during the final minute and last pair of FTs attempted in each of the games in the sample did not exceed 2 points. The shooting records of 92 players (32 guards, 32 forwards, 28 centers) were analyzed. The sample of shots included 116 pairs of FTs (234 total shots) attempted during the last minute of the games, and 104 last pair of FTs (208 total shots) attempted in those games. Table 1 displays the data for the different shots along with the age and experience of the shooters. Data on players' career FT efficiency were also collected. Following Worthy et al.'s (2009) approach for the analysis of the data, we considered separately each pair of FTs for each game situation (i.e., last minute FTs, last pair of FTs, and the players' career FTs' percentage).

\section{Design and Procedures}

In order to test for the validity of the raw data, a sub-sample of shot attempts (22 pairs of FTs) was randomly selected and coded by two independent qualified observers, who had more than 10 years of experience in performance analysis in basketball. The obtained coefficients of agreement (Kappa) were 1.0 for FTs made or missed and the score differential, with Kappa values for the variable "time left for the game to be ended" were greater than 0.96 . The local Institutional Review Board approved this study.

For each player, we collected the following data: FT shooting percentage during the final minute (60 s) and last pair of FTs attempted in the games, age, amount of experience at the professional level and playing position on the court (guard, forward, center; Trninić et al., 2000). Data were also obtained on the following contextual variables: the team's ability (team's ranking in the league on the current game day), competition stage (regular season vs. knockout), game location (home vs. away), score differential at the time of the shot, and time remaining for the game to end while the player was shooting.

A binomial logistic regression model was applied for the analysis of the data. The FT shooting statistics were included in the model as a dichotomous (categorical) variable, indicating whether players' performance during the closing moments of the game was lower, similar or better 
than their overall performance records. The score differential was also included in the model as a categorical variable, having the following categories: winning (if a team was ahead by 1 or 2 points), tied (no difference in the score), or losing (if a team was behind by 1 or 2 points). The player's age, his amount of experience at the professional level, the team's record, and the time remaining for the game to end were all included in the model as continuous variables.

\section{Statistical Analysis}

First, a descriptive analysis was performed, computing the means and standard deviations for the players' age, amount of experience, and FT percentage for each of the three conditions (career, last minute, last pair of FTs attempted).

Second, a repeated measures ANOVA was used to test for differences in the FT percentage between and within each playing position (guard, forward, center) for each of the three conditions. The Bonferroni post hoc test was applied when necessary to test for pairwise comparisons. The effect size (ES) estimations were calculated using the partial eta squared $\left(\eta p^{2}\right)$, and interpreted based on the following criteria: $.01=$ small effect, $.06=$ medium effect and $.14=$ large effect (Cohen, 1988).

Finally, a binomial Logistic Regression model was applied to estimate the regression weights and odds ratios (ORs) for the relationship between the players' characteristics and the contextual variables according to the players' decline in FTs performance. The dependent variable used in the model was:

$Y \in\{0,1\}$, with 0 (1) values for lower (similar or better) FTs performances compared to the players' records (Willoughby, 2002). Then, the model that was used was as follows:

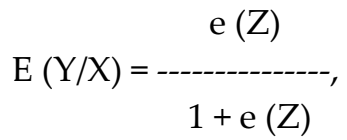

where $Z=ß 0+ß 1^{*}$ Age $+ß 2 *$ Experience + ß3*Playing position $+\beta 4^{*}$ Team ability + $155^{*}$ Competition Stage $+\beta 6^{*}$ Game Location + $B 7^{*}$ Seconds Remaining $+B 8^{*}$ Score differential + $\mathcal{E} \mathrm{I}$, and $\mathrm{BO}$ was the constant parameter.

This non-linear regression model uses the estimated regression coefficients as the estimated change in the log-odds, corresponding to a unit change in the explanatory (dependent) variable, while the other explanatory variables remain constant (Landau and Everitt, 2004). The ORs and their 95\% confidence intervals (CIs) were also calculated. The statistical analysis was performed using PASW Statistics (SPSS 22.0 version IBM Corp., Armonk, NY, US), and statistical significance was set at $p \leq .05$.

\section{Results}

Figure 1 displays the descriptive information for age, amount of experience and FT shooting percentage (career, last minute and last pair) for each of the playing positions; the significant differences were identified by the repeated measures ANOVA.

The data show that the differences in the shooting percentage were significant across conditions $\left(\mathrm{F}_{1,217}=14.565, p<.01 ; \mathrm{ES}=.06\right.$ medium effect, with greater values for the career percentage $)$ and playing position $\left(\mathrm{F}_{2,217}=18.401, p\right.$ $<.01 ; \mathrm{ES}=.15$ large effect), with the centers having the lowest performance compared to guards and forwards. The interactions between the FT shooting percentage and playing position were significant $\left(\mathrm{F}_{2,217}=4.043, p=.019 ; \mathrm{ES}=.036\right.$ small effect). The pairwise comparisons (Bonferroni post hoc) showed that the career percentage for centers was significantly lower than their teammates (centers $=69.4 \%$, forwards $=81.3 \%$, guards $=81.6 \%, p=.02$ ).

When looking at the final few minutes of the games, it could be noticed that while the shooting percentage for forwards was quite stable across all conditions (career $=81.3 \%$, last minute $=$ $80.3 \%$, last pair of FTs attempted $=80.8 \%, p=$ 0.864 ), a minor decrease in the success rate was observed for guards (career $=81.6 \%$, last minute $=$ $73.9 \%$, last pair of FTs attempted $=73.6 \%, p=$ .049). However, the largest decrease in the FT shooting percentage was detected for centers, as their career percentage $(69.4 \%)$ dramatically dropped in the last few minutes of the games, to $54.5 \%$ in the last minute and $54 \%$ in the last pair of FTs attempted $(p=.012)$. These figures are not much different from those of the Shaquille's FT shooting percentage. 
Table 1

Players' characteristics (age and experience) for each of the playing positions (mean $\pm s d$ ) and number of free-throws analyzed in the study.

\begin{tabular}{|c|c|c|c|c|}
\hline \multirow[b]{2}{*}{ Playing position } & \multirow[b]{2}{*}{ Age } & \multirow[b]{2}{*}{ Experience } & \multicolumn{2}{|c|}{ Free-throws (n) } \\
\hline & & & $\begin{array}{l}\text { Final minute } \\
\quad(\mathrm{n}=234)\end{array}$ & $\begin{array}{l}\text { Last pair } \\
(\mathrm{n}=208)\end{array}$ \\
\hline Guard & $28.6 \pm 4.0$ & $8.45 \pm 4.5$ & 80 & 82 \\
\hline Forward & $28.7 \pm 3.8$ & $7.14 \pm 4.4$ & 96 & 74 \\
\hline Center & $28.4 \pm 4.3$ & $7.15 \pm 4.7$ & 58 & 52 \\
\hline
\end{tabular}

Table 2

Effects of the independent variables on the players' decrease in the

FT shooting percentage during the final minute and last pair of FTs attempted in the games.

\begin{tabular}{|c|c|c|c|c|c|c|c|c|}
\hline \multirow{2}{*}{ Variables } & \multirow{2}{*}{$\mathrm{B}$} & \multirow{2}{*}{ S.E. } & \multirow{2}{*}{ Wald } & \multirow{2}{*}{$d f$} & \multirow{2}{*}{$p$} & \multirow{2}{*}{ OR } & \multicolumn{2}{|c|}{$95 \%$ CI } \\
\hline & & & & & & & Lower & Upper \\
\hline \multicolumn{9}{|l|}{ Final minute } \\
\hline Age & 0.13 & 0.08 & 2.63 & 1.00 & 0.10 & 1.14 & 0.97 & 1.32 \\
\hline Experience & 0.00 & 0.08 & 0.00 & 1.00 & 0.97 & 1.00 & 0.86 & 1.16 \\
\hline Playing position ${ }^{\mathrm{a}}$ & & & 8.06 & 2.00 & $0.02^{*}$ & & & \\
\hline Guard & $\begin{array}{l}0.72 \\
{[80]}\end{array}$ & 0.55 & 1.71 & 1.00 & 0.19 & 2.06 & 0.70 & 6.08 \\
\hline Center & $\begin{array}{l}1.58 \\
{[58]}\end{array}$ & 0.56 & 7.85 & 1.00 & $0.01^{* *}$ & 4.86 & 1.61 & 14.68 \\
\hline Team's ability & -0.02 & 0.05 & 0.21 & 1.00 & 0.65 & 0.98 & 0.89 & 1.07 \\
\hline Competition stage $^{b}$ & 1.31 & 0.81 & 2.66 & 1.00 & 0.10 & 3.72 & 0.77 & 18.03 \\
\hline Game locationc & 0.57 & 0.45 & 1.59 & 1.00 & 0.21 & 1.77 & 0.73 & 4.30 \\
\hline Seconds remaining & 0.01 & 0.01 & 0.18 & 1.00 & 0.67 & 1.01 & 0.98 & 1.03 \\
\hline Score differentiald & & & 2.36 & 2.00 & 0.31 & & & \\
\hline Tied & 0.36 & 1.02 & 0.13 & 1.00 & 0.72 & 1.44 & 0.20 & 10.55 \\
\hline Losing & -0.62 & 0.45 & 1.93 & 1.00 & 0.16 & 0.54 & 0.22 & 1.29 \\
\hline Intercept & -5.16 & 2.04 & 6.41 & 1.00 & $0.01^{* *}$ & 0.01 & & \\
\hline \multicolumn{9}{|l|}{ Last pair of FTs } \\
\hline Age & 0.10 & 0.10 & 1.07 & 1.00 & 0.30 & 1.11 & 0.91 & 1.35 \\
\hline Experience & -0.02 & 0.08 & 0.04 & 1.00 & 0.84 & 0.98 & 0.84 & 1.15 \\
\hline Playing position ${ }^{a}$ & & & 8.72 & 2.00 & $0.01^{*}$ & & & \\
\hline Guard & $\begin{array}{l}1.70 \\
{[82]}\end{array}$ & 0.71 & 5.69 & 1.00 & $0.02^{*}$ & 5.49 & 1.35 & 22.24 \\
\hline Center & $\begin{array}{l}2.22 \\
{[52]}\end{array}$ & 0.76 & 8.55 & 1.00 & $0.01^{* *}$ & 9.20 & 2.08 & 40.70 \\
\hline Team ability & -0.02 & 0.05 & 0.15 & 1.00 & 0.70 & 0.98 & 0.89 & 1.08 \\
\hline Competition stage $^{b}$ & -1.14 & 0.80 & 2.01 & 1.00 & 0.16 & 0.32 & 0.07 & 1.54 \\
\hline Game locationc & 0.24 & 0.53 & 0.21 & 1.00 & 0.64 & 1.27 & 0.45 & 3.57 \\
\hline Seconds remaining & 0.01 & 0.02 & 0.38 & 1.00 & 0.54 & 1.01 & 0.98 & 1.05 \\
\hline Score differentiald & & & 16.20 & 2.00 & $0.01^{* *}$ & & & \\
\hline Tied & -1.17 & 0.67 & 3.06 & 1.00 & $0.08^{*}$ & 0.31 & 0.08 & 1.15 \\
\hline Losing & -2.43 & 0.60 & 16.12 & 1.00 & $0.00^{* *}$ & 0.09 & 0.03 & 0.29 \\
\hline Intercept & -2.51 & 2.53 & 0.99 & 1.00 & 0.32 & 0.08 & & \\
\hline
\end{tabular}

S.E. = standard error; $O R=$ odds ratios; $C I=$ confidence intervals; the baseline categories when $O R=1$ are: a) forwards; b) regular season; c) playing at home; and d) winning.

In the parenthesis there is the number of observations for each position type. ${ }^{*} p<.05 ;{ }^{* *} p<.01$. 


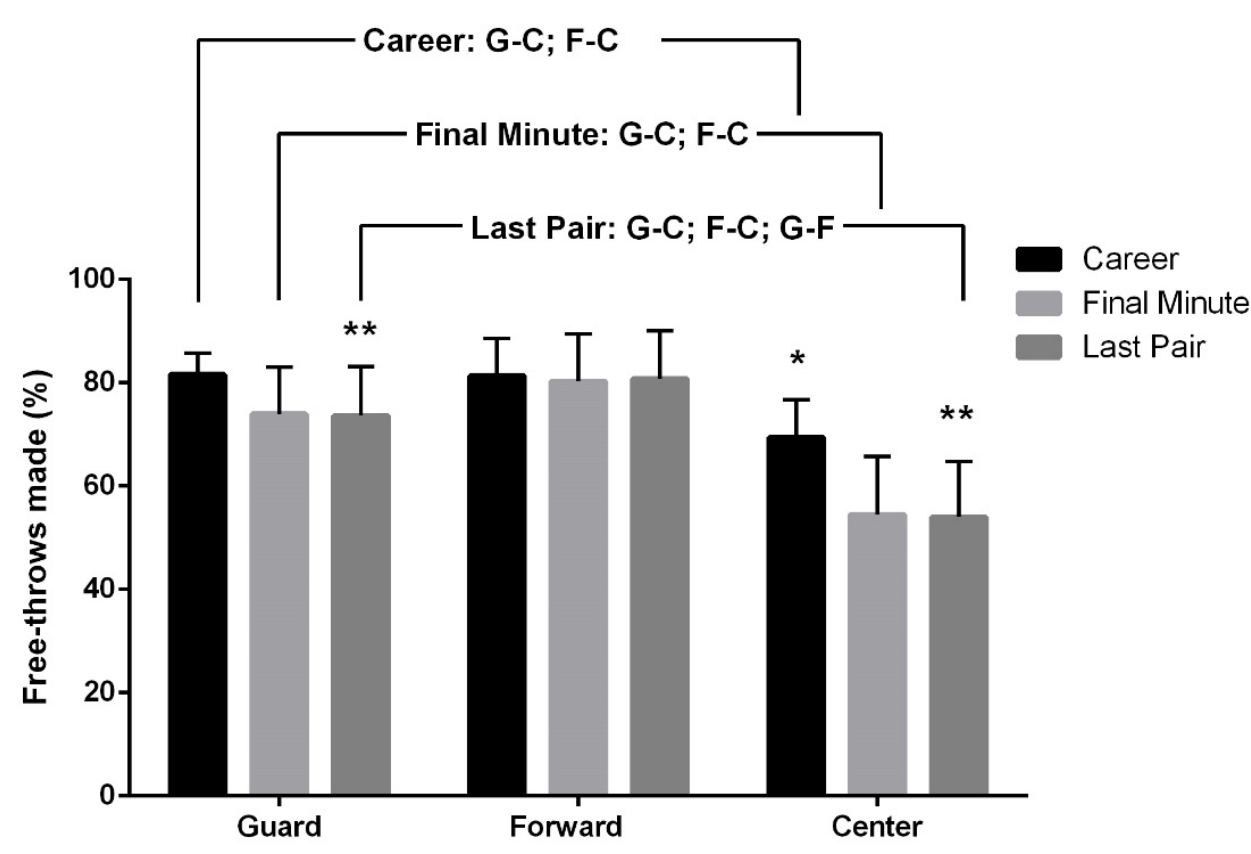

Playing position

Figure 1

Descriptive statistics of free-throws made (\%) for each of the playing positions (mean $\pm s d$ ).

*: significant differences between career and final minute FT percentage $p<.05$;

**: significant differences between career and last pair FT percentage $p<.05$;

G-C: significant differences between guards and centers $p<.05$;

F-C: significant differences between forwards and centers $p<.05$;

G-F: significant differences between guards and forwards $p<.05$.

Table 2 displays the results of the binomial logistic regression analysis. The results show that both models for the final minute $\left(\chi^{2} 10=\right.$ $22.08, p=.015)$ and last pair of FTs attempted $\left(\chi^{2} 10\right.$ $=34.64, p<.001)$ were statistically significant and correctly classified $74.1 \%$ and $76 \%$ of the cases, respectively. The results also show that the observed decline in players' performance during the last minute of the games was related to their playing position (baseline category for comparison when the OR $=1$ was the forward playing position), with a significantly higher probability for a decrease in the shooting percentage for the centers $(\mathrm{OR}=1.58)$ compared to the guard and forward players. The playing position was also associated with a decline in performance during the last pair of FTs attempted in the games for both guards $(\mathrm{OR}=1.70)$ and centers $(\mathrm{OR}=2.22)$, with the centers having a higher probability of missing the shots. 
Conversely, the score differential was associated with a lower probability for a player to miss the shots when his team was tied $(\mathrm{OR}=-1.17)$ or losing the game $(\mathrm{OR}=-2.43)$, than when the team was winning the game.

\section{Discussion}

This study was aimed at exploring possible determinants for the decrease of basketball FT shooting efficiency during the critical final moments of close basketball games. Several characteristics of the players, as well as context-related factors, that could be used to explain the previously observed decrease in FT shooting efficiency towards the end of a game, were examined. Our results confirmed previously reported findings (Bar-Eli and Tractinsky, 2000; Cao et al., 2011; Worthy et al., 2009) that showed a substantial decrease in players' FT shooting performance during the closing moments of the games, compared with their career percentage $(p<$ .001 with medium ES). Such a decline in athletic performance is attributed according to sport psychology literature to the increased likelihood that a mental performance crisis will occur (BarEli, 1997). This major effect is, among other things, a result of the immense pressure put on players by the need to score decisive FT points in close game situations, which increases their chances of choking (Beilock and Gray, 2007).

Interesting effects emerge when a closer look is taken into the data for the different playing positions. Overall, we found evidence for playing position and score differential to be important determinants of performance under these pressured conditions. In particular, FTs shooting efficiency for centers seems to be consistently lower than that of their teammates: centers do not only have the lowest career percentage (about $70 \%)$ in comparison to the other two positions (which have about $81-82 \%$ ), but this shooting percentage also radically decreases to about $54 \%$ under the extremely pressured conditions towards the end of the game (in comparison, the shooting percentage for forwards and guards is $80-81 \%$ and $74 \%$, respectively). Furthermore, the results of the regression models indicated a significantly higher chance for centers to miss their shots during the final minute and last pair of FTs attempted in the games.

Our results indicate that guards and, more particularly, forwards seem to cope with pressure much better than centers, at least as far as FTs in the last moments of close games are considered. These findings are in line with previous research (Sindik, 2015), which reported that guards and forwards were more successful in FTs than centers, but not entirely in line with Sampaio and colleagues (2006), who found evidence for the guards in the Spanish professional basketball league to be more successful in FT shooting than forwards and centers. In any case, the one-shared conclusion among these studies is related to the centers' relatively poorer performance in FT shooting.

An obvious question to be asked is: why are centers prone to be less successful at the foul line? Evidently, no clear answer is available, at least not one based on the current literature. However, it is possible that due to the fact that centers shoot throughout their career from shorter distances (i.e., as they have possession of the ball very often and shoot from "under the basket") and with their back to the basket, their spatial perception on the court most likely is quite different from that of guards and forwards. As a result, the ability of centers to successfully shoot while facing the basket from rather longer distances (e.g., FTs) is naturally lower compared to their teammates in the two other playing positions (Lidor, 2007). Moreover, it is also reasonable to assume that this relatively not very well-learned skill of the centers will suffer much more under high-pressure conditions, as previously suggested by the canonical behavioral literature (Hull, 1951; Spence, 1956).

Obviously, this line of argument should be investigated in future research, although it has substantial validity in the game's practice. It also finds support in current approaches that consider the experience accumulated through repeated practice as being the most crucial factor in developing expertise. For example, Gladwell (2008) argued that when studying the performance of "outliers" (i.e., highly successful, excellent performers), it should be taken into consideration that these outstanding people were given the opportunity to train and practice their respective skills much more intensively than the "usual" performers. Clearly, expert performance can be developed by deliberately practicing specific skills, as suggested by Ericsson (2003). 
Whether it is deliberate or not, demanding practice (Coyle, 2009) seems to play a major role in developing successful performers (Syed, 2010). Relating this view back to the case of guards and forwards, it appears that these players experience a much more arduous practice in shooting - with their face to the basket and from longer distances, including the practice of FTs, while centers lack this extensive experience.

From a tactical point of view, this might have some major consequences on the game play. For example, in the final pressured moments of close games, coaches hope to increase their team's chances of scoring, and thus often instruct their players to pass the ball to the centers who are situated close to the basket. On the one hand, this strategy of the coaches may result in an increased probability of the opponent (defensive) team to foul the centers. On the other hand, however, centers have the lowest probability of scoring from the foul line, and hence it seems beneficial for the defense to commit fouls especially against the centers. This conclusion finds support in previous research, which suggested that both inside and outside passes are needed during critical ball possessions, in order to increase their effectiveness through generating open situations for shooting (Mavridis et al., 2003). Furthermore, Fewell and colleagues (2012) found that elite basketball teams often demonstrated better control over the distribution of ball possession, with guards being the leaders of team's tactics. Then, the ball is passed towards the more skillful shooters in the critical game situations (e.g., forward shooters or centers in clear one-on-one situations).

From a performance analysis perspective, these results may indicate the changes in FT efficiency towards the end of a game by fatigue, especially if a FT was performed after an intensive transition from defense to offense during which the HR can rise to $170 / 180$ beats per min. In addition, increased fatigue can also cause a greater muscle tremor at the end of a game what may also affect the precision of FTs (Crowther et al., 2017). On the other hand, another element that can be considered is the mental disturbance by fans during a close game which can cause the loss of concentration (Gomez et al., 2015).

From a practical perspective, our results imply that coaches should integrate more intensive practice of FT shooting within their training sessions, with special attention to be paid to the center players (Lidor, 2007). In particular, FTs should be practiced under both "normal" and induced fatigue conditions, such as those at the end of training sessions or after high intensity exercises that involve high physical and mental fatigue. Following Kozar et al.'s (1994) suggestions, shooting should also be practiced under simulated clutch conditions in order to enhance the players' ability to better cope with pressure while shooting during the final minutes of actual games.

As for the coaches' role, it is suggested that players' FT performance, especially that of centers, should be improved through intensive training. It would be beneficial to include psychological intervention techniques in training programs. A special emphasis should therefore be put on centers, tailoring any program to the individual player in this position. Even though there is no guarantee that centers would become the best FT shooters, at least it could help in reducing the probability of remaining a "Shaq" in this respect throughout one's entire professional career.

\section{Conclusions}

Our results indicate that guards and forwards are more successful in FTs than centers in the last moments of close games. Evidently, centers seem to be real "problem athletes" (Ogilvie and Tutko, 1966), at least as far as FTs are concerned: their percentages are not only much lower throughout their career, but they also decrease most under pressure towards the end of a game, until they reach "Shaquille's order of magnitude" (i.e., slightly higher than $50 \%$ ). These conclusions should be reflected in the decisions made by coaches about how to conduct the game, especially during clutch situations, as well as the use of effective training programs for different playing positions. 


\section{References}

Bandura A. Social foundations of thought and action: A social cognitive theory. Englewood Cliffs, NJ: PrenticeHall; 1986

Bar-Eli M. Psychological performance crisis in competition, 1984-1996: A review. Eur Yearbook Sport Psych, 1997; 1 : 73-112

Bar-Eli M, Tenenbaum G, Elbaz G. A three-dimensional crisis-related analysis of perceived team performance. J Applied Sport Psych, 1991; 3: 160-175

Bar-Eli M, Tractinsky N. Criticality of game situations and decision making in basketball: An application of performance crisis perspective. Psych Sport Ex, 2000; 1: 27-39

Baumeister RF. Choking under pressure: self-consciousness and paradoxical effects of incentives on skilful performance. J Personality Social Psych, 1984; 46: 610-620

Beilock SL, Carr TH. When high-powered people fail working memory and "choking under pressure" in math. Psych Sci, 2005; 16: 101-105

Beilock SL, Gray R. Why do athletes "choke" under pressure? In G Tenenbaum, RC Eklund (Eds.), Handbook of sport psychology (3rd ed., pp. 425-444). Hoboken, NJ: Wiley; 2007

Beilock SL, Gray R. From attentional control to attentional spillover: A skill-level investigation of attention, movement, and performance outcomes. Hum Movement Sci, 2012; 31: 1473-1499

Beilock SL, Kulp CA, Holt LE, Carr TH. More on the fragility of choking under pressure in mathematical problem solving. J Exp Psych, 2004; 133: 584-600

Cao Z, Price J, Stone DF. Performance under pressure in the NBA. J Sports Econ, 2011; 12: 231-252

Castaneda B, Gray R. Effects of focus of attention on baseball batting performance in players of differing skill levels. J Sport Ex Psych, 2007; 29: 60-77

Cohen J. Statistical power analysis for the behavioral sciences ( $2^{\text {nd }}$ ed.). Hillsdale, NJ: Erlbaum; 1988

Coyle D. The talent code. New York, NY: Bantam; 2009

Crowther RG, Leicht AS, Pohlmann JM, Shakespear-Druery J. Influence of Rest on Players' Performance and Physiological Responses during Basketball Play. Sports, 2017; 5: 27.

DeCaro MS, Thomas RD, Albert NB, Beilock SL. Choking under pressure: multiple routes to skill failure. J Exp Psych: General, 2011; 140: 390-406

Ericsson KA. Development of elite performance and deliberate practice. In J Starkes, KA Ericsson (Eds.), Expert performance in sports (pp. 49-83). Champaign, IL: Human Kinetics; 2003

Ferreira AP, Volossovitch A, Sampaio J. Towards the game critical moments in basketball: a grounded theory approach. Int J Perf Anal Sport, 2014; 14: 428-442

Fewell JH, Armbruster D, Ingraham J, Petersen A, Waters JS. Basketball teams as strategic networks. Plos One, 2012; 7(11): e47445

FIBA Official basketball rules. Barcelona, Spain. FIBA Central Board; 2014

Gabel A, Redner S. Random walk picture of basketball scoring. J Quant Anal Sports, 2012; 8(1)

Gladwell M. Outliers: The story of success. New York, NY: Back Bay; 2008

Goldman M, Rao JM. Effort vs. concentration: The asymmetric impact of pressure on NBA performance, Proceedings MIT Sloan Sports Analytics Conference, Boston, MA, 1-10; 2012

Gómez MA, Lorenzo A, Jiménez S, Navarro RM, Sampaio J. Examining choking in basketball: effects of game outcome and situational variables during last 5 minutes and overtimes. Percept Mot Skills, 2015; 120: $111-124$

Hill DM, Hanton S, Fleming S, Matthews N. A re-examination of choking in sport. Eur J Sport Sci, 2009; 9: 203-212

Hull C. Essentials of behavior. New Haven, CT: Yale University Press; 1951

Kahneman D, Tversky A. Prospect theory: An analysis of decision under risk. Econometrica, 1979; 47: 263-291

Kozar B, Vaughn RE, Whitfield KE, Lord RH, Dye B. Importance of free-throws at various stages of basketball games. Percept Mot Skills, 1994; 78: 243-248

Landau S, Everitt B. A handbook of statistical analyses using SPSS. Boca Raton, FL: Chapman \& Hall/CRD; 2004

Lewin K. Field theory in social science. New York, NY: Harper; 1951

Liao CM, Masters RS. Self-focused attention and performance failure under psychological stress. J Sport Exer 
Psych, 2002; 24: 289-305

Lidor R. Preparatory routines in self-paced events. In G Tenenbaum, RC Eklund (Eds.), Handbook of sport psychology (3rd ed., pp. 445-465). Hoboken, NJ: Wiley; 2007

Malarranha J, Figueira B, Leite N, Sampaio J. Dynamic modeling of performance in basketball. Int J Perf Anal Sport, 2013; 13: 377-387

Mavridis G, Laios A, Taxildaris K, Tsiskaris G. Developing offense in basketball after a return pass outside as crucial factor of winning. Inq Sport Phys Ed, 2003; 2: 81-86

Ogilvie BC, Tutko TA. Problem athletes and how to handle them. London, UK: Palham; 1966

Oudejans RR, Kuijpers W, Kooijman CC, Bakker FC. Thoughts and attention of athletes under pressure: skill-focus or performance worries? Anxiety, Stress Coping, 2011; 24: 59-73

Sampaio J, Janeira M, Ibáñez S, Lorenzo A. Discriminant analysis of game-related statistics between basketball guards, forwards and centers in three professional leagues. Eur J Sport Sci, 2006; 6: 173-178

Schmidt RA, Wrisberg CA. Motor learning and performance: A problem-based learning approach. Champaign, IL: Human Kinetics; 2004

Sindik J. Performance indicators of the top basketball players: relations with several variables. Coll Antropol, 2015; 39: 617-624

Solomonov Y, Avugos S, Bar-Eli M. Do clutch players win the game? Testing the validity of the clutch player's reputation in basketball. Psych Sport Ex, 2015; 16: 130-138

Spence K. Behavior theory and conditioning. New Haven, CT: Yale University Press; 1956

Syed M. Bounce: Mozart, Federer, Picasso, Beckham and the science of success. New York, NY: HarperCollins; 2010

Trninić S, Dizdar D, Dežman B. Empirical verification of the weighted system of criteria for the elite basketball players' quality evaluation. Coll Antropol, 2000; 24: 443-455

Willoughby KA. Winning games in Canadian football: A logistic regression analysis. College Math J, 2002; 33: 215-220

Worthy DA, Markman AB, Maddox WT. Choking and excelling at the free-throw line. Int J Creat Problem Solv, 2009; 19: 53-58

Zuzik P. Free-throw shooting effectiveness in basketball matches of men and women. Sport Sci Rev, 2011; 20: $149-160$

\section{Corresponding author:}

\section{Miguel-Ángel Gómez-Ruano}

Faculty of Physical Activity and Sport Sciences,

Polytechnic University of Madrid,

C/ Martín Fierro s/n; 28040, Madrid, Spain.

Tel: +34 913364143

E-mail: magor_2@yahoo.es 